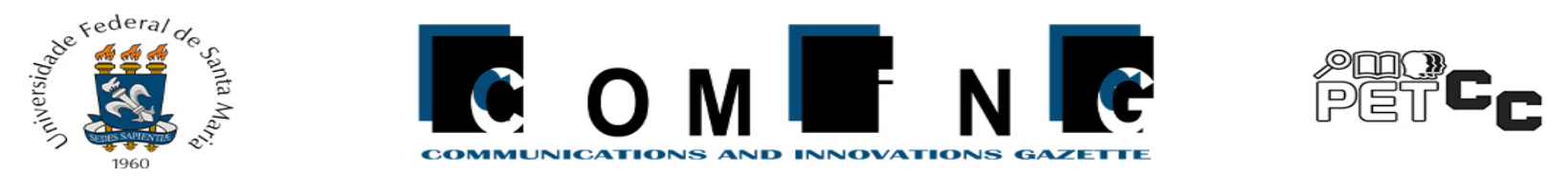

\title{
Oficina da ciência da Terra como auxiliar no processo educacional
}

\author{
Jean Lucas Vinhas Medeiros, Ana Maria Souza dos Santos Moreau
}

PET Solos: agregando saberes. Departamento de Ciências Agrárias e Ambientais Universidade Estadual de Santa Cruz. Campus Soane Nazaré de Andrade, Rodovia Jorge Amado, km 16, Bairro Salobrinho. CEP 45662-900. Ilhéus-Bahia

vinhasmedeiros@gmail.com, amoreau@uesc.br

\begin{abstract}
The TEP(Tutorial Education Program) Soils: aggregating knowledge from UESC's Agronomy and Geography courses (Santa Cruz State University), since 2011, has held the Earth Science Workshop as a way of spreading geosciences through experiments and models idealized to bring schoolchildren to the object of study, the Earth. In order to evaluate the efficiency of the referred methodology, questionnaires were applied to teachers before and after the intervention. In general, a higher success rate was obtained after the workshop was held, confirming this format chosen for the approach and interaction as effective for the training of educators and later dissemination to their students. This workshop is an important complementary tool for teaching in Basic Education.
\end{abstract}

Resumo. O PET (Programa de Educação Tutorial) Solos: agregando saberes, dos cursos de Agronomia e Geografia da Universidade X, desde o ano de 2011, realiza a Oficina da Ciência da Terra como forma de difusão das geociências através de experimentos e maquetes idealizados para aproximar escolares do objeto de estudo, a Terra. Objetivando avaliar a eficiência da referida metodologia, questionários foram aplicados com professores antes e após a intervenção. No geral, obteve-se maior índice de acertos após a realização da oficina, ratificando este formato escolhido para a abordagem e interação como eficaz para a capacitação de educadores e posterior difusão para seus estudantes. Essa oficina constitui uma ferramenta complementar importante para o exercício docente na Educação Básica.

\section{Introdução}

O papel e atuação contemporâneo das escolas e dos meios de comunicação social na divulgação científica configuram-se de fundamental importância. Para além das novas teorias sobre esse tema, pode-se presenciar a atuação proativa e competente de instituições de ensino e do campo midiático na divulgação da ciência, pesquisas e projetos universitários. Houve grande transformação, inclusive proporcionada por projetos dos grupos do Programa de Educação Tutorial - PET, como já relatado nas pesquisas de [Rosin, Gonçalves e Hidaldo 2017; Peres et al. 2014; Martin 2005; Torina, Almeida e Paula 2016; Rodrigues et al. 2014; Ferreira 2011; Walter 2010; Drebes 2012].

Cabe acrescentar, também, que trabalhos de [Bacich e Moran 2018, 2015; Amara 2019; Lázaro, Sato e Tezani 2018; Rothstein e Gonçalves Santos 2017; Moran 2017, 
2015], já apontaram uma série de desafios da educação contemporânea. Esses podem ser enfrentados através das metodologias ativas, buscando sempre uma educação inovadora com abordagens teóricas e, principalmente, práticas. Nessa perspectiva, os estudantes devem assumir papéis de protagonistas no processo educacional, onde a criatividade e a colaboração são fundamentais.

Ainda, o ensino híbrido já é uma realidade da educação contemporânea, principalmente frente a recente conjuntura mundial. Nesse sentido, práticas interdisciplinares tornam-se cada vez mais necessárias, principalmente às relacionadas as metodologias ativas nos diversos níveis de ensino, transformando o papel do docente tanto no ensino presencial quanto no online e/ou offline. Esse "enlace" de experiências pedagógicas faz com que os profissionais da educação "reaprendam" a ensinar, agora, intermediando o conhecimento com foco nos educandos.

Pressupostos de ensino-aprendizagem contemporâneos reconhecem a superioridade do trabalho cooperativo em prover uma oportunidade de endossar e encorajar pensamentos de alto nível e processos de raciocínio, devido à interação social [Trumper 2003]. Tem sido demonstrado, por exemplo, que a partir da utilização de materiais de baixo custo encontrados no cotidiano, é possível propiciar aulas mais atraentes e motivadoras, resultando em maior envolvimento dos estudantes na construção do conhecimento [Souza, Andrade e Nascimento Junior 2008].

De fato, a educação não formal possui características próprias quanto à autonomia do visitante na busca do saber, o que favorece a ampliação e o refinamento cultural em um ambiente capaz de despertar emoções que se tornem aliadas de processos cognitivos dotados de motivação intrínseca para a aprendizagem [Pozo e Crespo 1998]. Com isso, um novo campo da educação se estrutura: o da educação não formal [Gohn 1999]. Não basta dizer, é preciso fazer e mostrar; é necessário sair de um processo de ensino formal para um sistema de aprendizagem mais espontâneo onde a sala de aula seja apenas um de seus elementos [Laburú, Carvalho e Batista 2001]. Essas teorias e concepções são dialogadas por Karling (1991), Vigotsky (1987), Zabala (1998), Piaget (1971), Moacir (1996) e outros que sustentam uma postura diferente dos professores perante a educação, cujo uso dos recursos didáticos são fundamentais para dar sentido e significado aos conhecimentos e saberes colocados à disposição dos estudantes.

Montenegro (2005) reforça essa ideia afirmando que, nos ensinos fundamental e médio, os colegiais devem trabalhar com modelos sólidos e com material visual. Dessa forma, cabe ao educador buscar metodologias que motivem os escolares, debatendo temáticas da realidade vivida por eles. Nesse sentido, faz-se necessário o uso de metodologias didático-pedagógicas de ensino voltadas tanto para a Educação Básica, como o trabalho desenvolvido por Policarpo, Fuhr e Librelotto (2019); quanto o Ensino Superior [Jurgina et al. 2019].

O trabalho de Stefenon (2014) apontou que, a presença de temáticas relacionadas ao estudo de rocha, solo e relevo, portanto, das geociências, são escassas no currículo escolar. Quando presentes, são dialogadas por práticas tradicionais de ensino que não despertam a curiosidade dos estudantes para esses temas que são tão atuais e urgentes. Conscientes dessa problemática e imbuídos no compromisso de difusão da Ciência do Solo, o PET (Programa de Educação Tutorial) Solos: agregando saberes, da Universidade Estadual de Santa Cruz - UESC, executa, desde 2011, um projeto de ensino, pesquisa e extensão denominado "Oficina da Ciência da Terra". Tal ação é fruto da constatação dos 
docentes das disciplinas iniciais ligadas à temática das geociências/ciência do solo, bem como da dificuldade vivenciada pelos estudantes dos cursos de Agronomia, Biologia e Geografia da UESC em compreender os conteúdos relativos ao meio físico.

Segundo Amorim e Moreau (2003), o problema inicia-se no ensino básico pela forma fragmentada, não sequenciada, resumida e equivocada que os temas referentes às geociências são tratados nos livros didáticos. Para Lima (2002), existe uma inadequação das aulas ministradas sobre essas temáticas em consequência da própria formação dos professores nos cursos de licenciatura das universidades, como consequência, não executam a transposição didática dos conteúdos referentes ao meio físico em suas práticas docentes na educação básica.

Assim, a Oficina da Ciência da Terra foi concebida para atender tanto estudantes e professores dos ensinos fundamental e médio quanto universitários, com o intuito de conduzi-los à percepção de que existe uma inter-relação entre as quatro esferas que constituem a Terra (atmosfera, hidrosfera, litosfera e biosfera) e que elas atuam nos processos de formação e evolução dos solos. Com isso, aprimora-se e difunde-se o conhecimento produzido sobre solo, essa ínfima porção do nosso planeta que, apesar de corresponder a uma porcentagem muito pequena do raio da Terra $(0,00003 \%)$, é a base para a vida e, pouca atenção tem sido dispensada a ele.

Para Paviani e Fontana (2009), "oficina é uma oportunidade de vivenciar situações concretas e significativas, baseada no tripé: sentir-pensar-agir, com objetos pedagógicos". Para as autoras, a metodologia da oficina, ao mudar o foco tradicional da aprendizagem (cognição), possibilita a apropriação, construção e produção de conhecimentos teóricos e práticos, de forma ativa e reflexiva.

A presente pesquisa teve como objetivo propor um modelo de oficina na abordagem dos conteúdos de geociências e verificar se o formato escolhido para a interação com os professores, por meio da utilização de materiais didático-pedagógicos, foi uma metodologia de trabalho eficaz na capacitação coletiva destes.

\section{Metodologia}

Foi utilizada a metodologia da oficina no processo de ensino-aprendizagem dos temas relativos à Ciência da Terra.

As referências utilizadas na escolha dos temas para a oficina, materiais e experimentos produzidos foram: Guia Prático de Ciências: "como a Terra funciona" [Farndon 1994], Decifrando a Terra [Teixeira et al. 2007], Manual Técnico de Pedologia [IBGE 2015], 19 Lições de Pedologia [Lepsch 2011], Sistema Brasileiro de Classificação de Solos [Embrapa 2018]. Além dessas referências, o site do Programa de Extensão Universitária Solo na Escola (UFPR), Programa de Extensão Universitária Solo na Escola (Esalq) e Projeto Solo na Escola (UFCG), também foram consultados. Cada uma dessas referências embasaram a confecção de experimentos específicos da oficina, conforme observado no Quadro 1. 


\section{Quadro 1. Contribuição das referências na elaboração e montagem dos experimentos da Oficina da Ciência da Terra}

\begin{tabular}{|c|c|}
\hline REFERÊENIA & EXPERIMENTO \\
\hline $\begin{array}{c}\text { Guia Prático de Ciências: "como a } \\
\text { Terra funciona" }\end{array}$ & $\begin{array}{c}\text { Maquete vulcão; Globo estrutura interna da Terra; } \\
\text { Correntes de convecção; Maquete placas } \\
\text { tectônicas }\end{array}$ \\
\hline Decifrando a Terra & $\begin{array}{c}\text { Maquete vulcão; Exposição tipos de rochas; } \\
\text { Globo estrutura interna da Terra; Correntes de } \\
\text { convecção; Maquete placas tectônicas }\end{array}$ \\
\hline Manual Técnico de Pedologia & $\begin{array}{c}\text { Tabuleiro cores do solo; Amostras das frações do } \\
\text { solo; Mini monolitos 3D de perfis de solos; } \\
\text { Monolitos de perfis de solos representativos da } \\
\text { Bahia }\end{array}$ \\
\hline 19 Lições de Pedologia & $\begin{array}{c}\text { Intemperismo, Gênese dos Solos e seus atributos; } \\
\text { Maquete uso e ocupação do solo; Amostras das } \\
\text { frações do solo; Erosão eólica }\end{array}$ \\
\hline Sistema Brasileiro de & $\begin{array}{c}\text { Tabuleiro cores do solo; Mini monolitos 3D de } \\
\text { perfis de solos; Monolitos de perfis de solos } \\
\text { representativos da Bahia }\end{array}$ \\
\hline Programa de Extensão & $\begin{array}{c}\text { Maquete vulcão; Globo estrutura interna da Terra; } \\
\text { Maquete uso e ocupação do solo; Maquete placas } \\
\text { tectônicas; Erosão eólica }\end{array}$ \\
\hline Universitária Solo na Escola \\
(UFPR)
\end{tabular}

Além das referências apresentadas anteriormente, os integrantes do grupo desenvolveram e produziram maquetes contextualizadas às problemáticas regionais de uso e ocupação dos solos, bem como, adaptaram experimentos dos solos representativos do Sul da Bahia.

A oficina foi apresentada para um grupo de vinte professores da educação básica de colégios públicos da microrregião Ilhéus-Itabuna (Bahia). Com estes mesmos professores, foram aplicados quarenta questionários no total, vinte antes e vinte após a intervenção metodológica proposta.

Como forma de facilitar a compreensão, a oficina foi montada seguindo uma ordem cronológica de apresentação dos assuntos e foi subdividida em quatro eixos: Eixo 1 - O planeta Terra e a sua dinâmica; Eixo 2 - A litosfera e a formação do solo; Eixo 3 - Os solos se diferenciam em quê?; Eixo 4 - Uso e conservação do solo.

\subsection{Eixo 1 - O planeta Terra e a sua dinâmica}

A estrutura dinâmica da Terra é baseada em características de rigidez. Desta forma, ela pode ser dividida em: litosfera, astenosfera, mesosfera e núcleo. Os equipamentos preparados nesse eixo foram pensados para explicar de forma lúdica as dinâmicas destas camadas. 
Os materiais didáticos confeccionados nesse eixo foram: globo terrestre adaptado, experimento de correntes de convecção, vulcão e maquete das placas tectônicas. A aplicabilidade desses materiais permite compreender a dinâmica da Terra, enfatizando as relações existentes entre os processos internos e externos da sua formação e que, a partir do movimento das correntes de convecção, a litosfera fragmentada em placas tectônicas se desloca e garante a renovação das rochas. Os conteúdos explorados nesse eixo foram: estrutura interna da Terra, magmatismo, vulcanismo e tectônica de placas.

\subsection{Eixo 2 - A litosfera e a formação do solo}

A litosfera é a camada da Terra compreendida entre a atmosfera e a astenosfera. Podemos defini-la como a camada constituída pelas rochas da esfera terrestre, formada tanto pela crosta continental quanto a oceânica. Nesse eixo, buscou-se representar como os diferentes tipos de materiais de origem podem influenciar na gênese dos solos.

Nesse eixo foram utilizados: caixas de rochas e minerais e experimento de intemperismo químico, com demonstração da reação química do ácido clorídrico em rochas calcárias. Após as abordagens do eixo 1, buscou-se com estes materiais simplificar o entendimento sobre os ciclos das rochas, permitindo a compreensão de como se processam as reações de intemperismo químico na transformação de um material resistente e cristalino em outro friável, permeável à água e com capacidade produtiva. Os conteúdos explorados nesse eixo foram: petrologia e intemperismo.

\subsection{Eixo 3 - Os solos se diferenciam em quê?}

Um conceito oficial da ciência do solo é dado pela Embrapa (2018), que considera o solo como corpos naturais, formados por partes sólidas, líquidas e gasosas, contendo materiais minerais e orgânicos e que se encontram no manto superficial do planeta, podendo conter matéria viva, ser vegetados e ter sofrido modificações antrópicas. Popularmente, ele é conhecido como sendo "a terra", aquilo em que pisamos; mas, sob o ponto de vista da Geografia, é o espaço utilizado e transformado pelo homem e pelos demais seres vivos, sendo, portanto, uma importante fonte de vida. Nesse eixo, apresentam-se materiais para exemplificar os diferentes tipos de solos presentes no Brasil.

Nesse eixo confeccionou-se: mini monolitos com sequência de perfis representativos da evolução do solo; experimento com ímã demonstrando a eletropositividade dos solos oxídicos; caixa de cores dos solos, onde enfatiza-se a diversidade de interação dos agentes pigmentantes para determinação da cor do solo e sua interpretação. $O$ objetivo desse eixo foi demonstrar como a gênese do solo resulta em características morfológicas, físicas e químicas próprias e definidoras de cada classe e como as mesmas distinguem os solos. Os conteúdos explorados nesse eixo foram: fatores de formação dos solos, processos pedogenéticos, composição, atributos dos solos e variação do solo na paisagem.

\subsection{Eixo 4 - Uso e conservação do solo}

A conservação do solo é um conjunto de princípios e técnicas que visa o manejo correto das terras, evitando a erosão em todas suas formas. Seu objetivo é aproveitar a terra através do uso sustentável. Assim, evita-se a degradação física, química e biológica do solo. Nesse eixo, buscou-se sensibilizar os participantes da oficina sobre o correto uso do solo e a importância de sua conservação para manutenção da vida no planeta Terra. 
Elaborou-se nesse eixo: maquetes de uso do solo urbano, rotação de cultura, bacia hidrográfica e experimento dos processos erosivos. Objetiva-se com esses materiais sensibilizar professores e estudantes sobre a importância do uso sustentável do solo, buscando técnicas de manejo que venham mitigar a degradação, além de enfatizar questões relacionadas ao planejamento urbano. Os conteúdos explorados nesse eixo foram: uso e ocupação do solo, técnicas de conservação do solo, hidrografia e erosão.

Parte das maquetes, amostras, experiências e materiais apresentados nos eixos a priori aqui elencados, são exibidos na Figura 1.

\section{Figura 1. Parte dos materiais didático-pedagógicos confeccionados pelo PET Solos da UESC e utilizados na Oficina da Ciência da Terra}
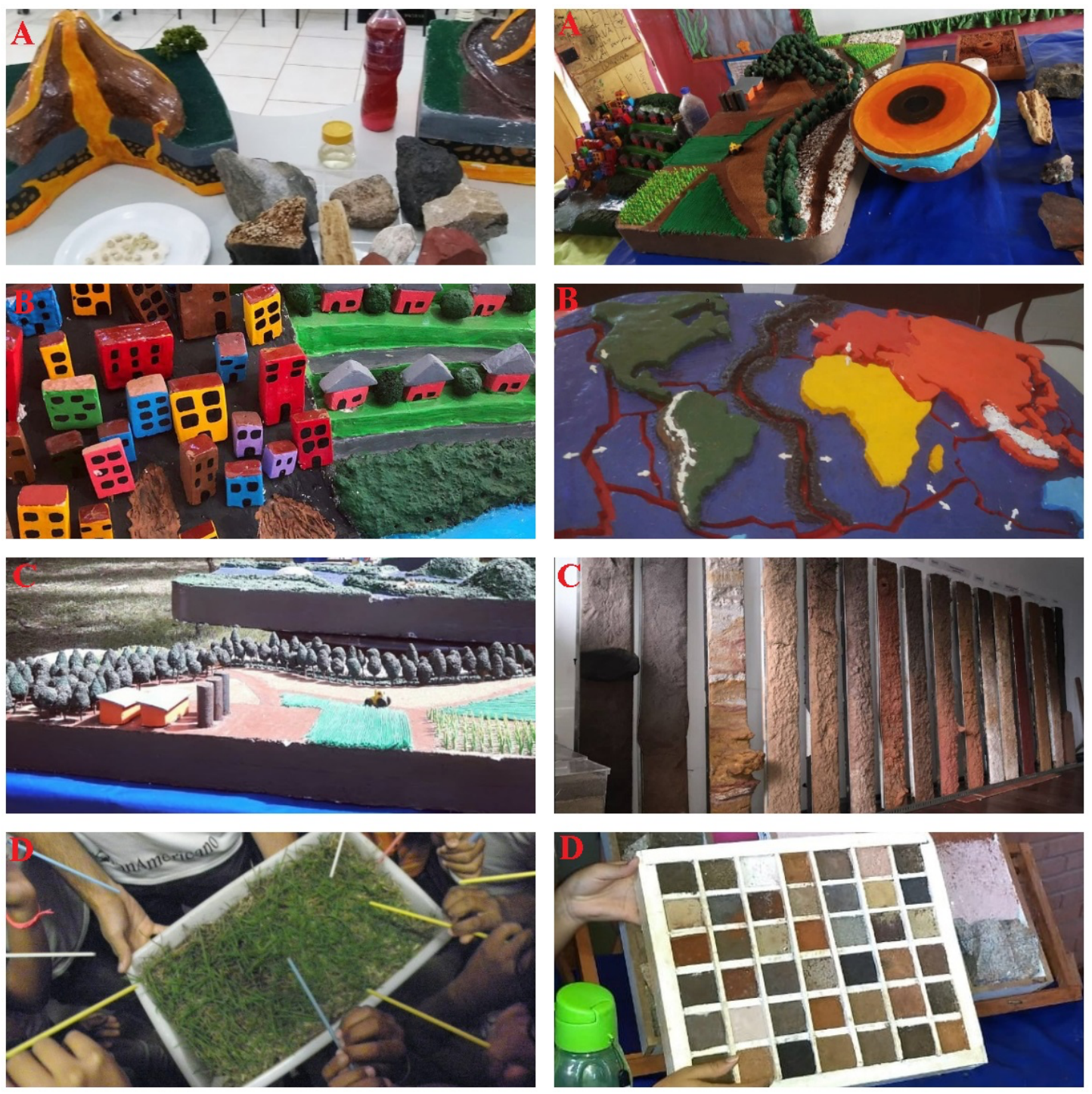

Legenda: A - Experimentos dos eixos 1, 2 e 4; B - Experimentos dos eixos 2, 3 e 4; C - Experimentos dos eixos 1, 3 e 4; D - Experimentos dos eixos 2, 3 e 4. 


\section{Resultados e Discussão}

A oficina foi apresentada para um grupo de vinte professores da educação básica de colégios públicos da microrregião Ilhéus-Itabuna (Bahia). Os docentes lecionam as disciplinas de Geografia, Biologia, Química, Ciências e Meio Ambiente em quarenta escolas distribuídas em quarenta e um municípios na região, totalizando cerca de dois mil e seiscentos estudantes atendidos por esses profissionais.

Cabe ressaltar que, com exceção dos professores de Química e Biologia, os cursos de formação universitária dos docentes participantes, apresentam nos seus Projetos Acadêmicos Curriculares matérias relacionadas às geociências, logo, esses docentes tiveram uma educação acadêmica voltada, também, ao conhecimento, por exemplo, das disciplinas Geologia e Pedologia.

Para verificar se os materiais didático-pedagógicos confeccionados e utilizados na oficina foram eficazes no processo de ensino-aprendizagem dos conteúdos, foram aplicados quarenta questionários no total, vinte antes e vinte após a intervenção metodológica proposta. As questões foram elaboradas correlacionando-as com a estrutura dos temas apresentados e já citados anteriormente nesse trabalho. Os questionários continham vinte e cinco questões relacionadas às ciências da Terra com os seguintes assuntos: origem do universo; estrutura interna da Terra; magmatismo; tectônica de placas; vulcanismo; petrologia; intemperismo; gênese do solo; atributos diagnósticos dos solos; Sistema Brasileiro de Classificação de Solos; planejamento e uso da terra; questões ambientais. Após todo o processo da intervenção, os dados foram tabulados no software Microsoft Office 365 Excel, com o intuito de facilitar o entendimento e a análise final dos resultados da pesquisa.

Os resultados obtidos demonstraram que antes da intervenção da oficina os professores de Ciências foram os que obtiveram um maior número de acertos nas questões relacionadas à ciência do solo, e, após a apresentação, os docentes de Geografia, demonstrando uma maior facilidade no entendimento dos conteúdos relacionados a Geologia e Pedologia. No geral, pôde-se constatar predominância de acertos entre os docentes das outras matérias, após a intervenção.

Além da influência da própria oficina, a formação superior dos profissionais através das estruturas apresentadas nos respectivos Projetos Acadêmicos Curriculares, também pode ter colaborado no resultado da pesquisa. Ainda, como já comentado a priori, com exceção dos professores de Química e Biologia, os docentes das outras matérias possuem em suas formações acadêmicas componentes de Geologia e Pedologia. Esse é um fator importante, especialmente considerando a relevância da experiência prévia nos processos de aprendizagem. Nesse sentido, defende-se a inclusão de disciplinas relacionadas à ciência do solo nas matrizes curriculares dos cursos de Química e Biologia, tendo em vista que conteúdos como: a origem dos elementos químicos; a composição química do magma e da crosta terrestres; os organismos que agem como um dos fatores de formação dos solos; a importância do solo para garantir a vida no planeta Terra; a composição química dos diferentes tipos de rochas; os processos de intemperismo químico; a matéria orgânica que compõe o solo; processos pedogenéticos influenciados pelas reações químicas; a interação de fatores e processos químicos e biológicos na diferenciação dos solos na paisagem e consequentemente influenciando o uso e ocupação destes, etc.; são comuns a essas ciências, justificando, assim, tal sugestão de inclusão dos componentes nas estruturas curriculares acadêmicas dos cursos. 
As questões com menos acertos foram àquelas relacionadas às temáticas da estrutura interna da Terra e magmatismo, contempladas pelo globo terrestre e o experimento das correntes de convecção. As perguntas com maior número de acertos foram as relativas à origem do universo e a tectônica de placas (após intervenção). Estas foram contempladas nos experimentos com maior apelo visual e cujos assuntos são correlacionados a outros experimentos da oficina, tais como, estrutura interna da Terra, vulcanismo e coleção de rochas. O número de acertos para cada uma das questões, antes e depois da realização da Oficina de Ciência da Terra, pode ser verificado a seguir no Quadro 2.

\section{Quadro 2. Número de acertos para cada uma das questões, antes e depois da realização da Oficina da Ciência da Terra}

\begin{tabular}{|c|c|c|c|c|c|c|c|c|c|c|c|c|c|}
\hline \multicolumn{10}{|c|}{ QUESTÕES } \\
\hline & $\mathbf{1}^{\mathbf{a}}$ & $\mathbf{2}^{\mathbf{b}}$ & $\mathbf{3}^{\mathbf{c}}$ & $\mathbf{4}^{\mathbf{d}}$ & $\mathbf{5}^{\mathbf{d}}$ & $\mathbf{6}^{\mathbf{d}}$ & $\mathbf{7}^{\mathbf{d}}$ & $\mathbf{8}^{\mathbf{d}}$ & $\mathbf{9}^{\mathbf{d}}$ & $\mathbf{1 0}^{\mathbf{d}}$ & $\mathbf{1 1}^{\mathbf{b}}$ & $\mathbf{1 2}^{\mathrm{e}}$ & $\mathbf{1 3}^{\mathbf{f}}$ \\
\hline ANTES & 19 & 14 & 0 & 10 & 19 & 17 & 14 & 13 & 13 & 4 & 9 & 15 & 15 \\
\hline APÓS & 20 & 16 & 1 & 13 & 20 & 18 & 20 & 17 & 14 & 5 & 10 & 16 & 16 \\
\hline
\end{tabular}

\begin{tabular}{|c|c|c|c|c|c|c|c|c|c|c|c|c|c|}
\hline \multicolumn{10}{|c|}{ QUESTÕES } \\
\hline & $\mathbf{1 4}^{\mathbf{g}}$ & $\mathbf{1 5}^{\mathbf{g}}$ & $\mathbf{1 6}^{\mathbf{g}}$ & $\mathbf{1 7}^{\mathbf{h}}$ & $\mathbf{1 8}^{\mathbf{i}}$ & $\mathbf{1 9}^{\mathbf{i}}$ & $\mathbf{2 0}^{\mathbf{i}}$ & $\mathbf{2 1}^{\mathrm{i}}$ & $\mathbf{2 2}^{\mathbf{i}}$ & $\mathbf{2 3}^{\mathbf{i}}$ & $\mathbf{2 4}^{\mathbf{i}}$ & $\mathbf{2 5}^{\mathbf{i}}$ & TOTAL DE ACERTOS (\%) \\
\hline ANTES & 2 & 2 & 15 & 1 & 6 & 13 & 2 & 8 & 10 & 18 & 9 & 1 & 49,8 \\
\hline APÓS & 5 & 4 & 18 & 2 & 7 & 15 & 3 & 9 & 11 & 20 & 10 & 2 & 58,4 \\
\hline
\end{tabular}

Legenda: Questões relacionadas - Eixo 1: O planeta Terra e a sua dinâmica Assuntos: aorigem do universo; bestrutura interna da Terra; ' ${ }^{2}$ magmatismo; dtectônica de placas; evulcanismo / Eixo 2: A litosfera e a formação do solo - Assuntos: fpetrologia; gintemperismo; hgênese do solo / Eixo 3: Os solos se diferenciam em quê? - Assuntos: iatributos diagnósticos; iSistema Brasileiro de Classificação de Solos / Eixo 4: Uso e conservação do solo - Assuntos: iplanejamento e uso da terra; iquestões ambientais.

Questões relacionadas à origem do universo, tectônica de placas e solos obtiveram $100 \%$ de acertos após a intervenção da oficina. As perguntas com maior discrepância/diferença entre o total de acertos antes e depois, foram as relacionadas às temáticas da tectônica de placas.

Calculando a variação percentual de cada eixo, comparando o antes e o depois, obteve-se $17,75 \%$ de média no eixo $1,20 \%$ no eixo 2 e 12,5\% nos eixos 3 e 4 , demostrando, assim, uma maior eficácia nos experimentos da oficina confeccionados para os assuntos relacionados à litosfera e a formação do solo.

O trabalho de Locatelli et al. (2009) apontou que a maioria dos professores da rede pública de ensino do Rio Grande do Sul e Santa Catarina afirmaram que não há capacitação sobre meio ambiente nos estados e que entre as experiências relacionadas à 
sustentabilidade, apenas poucos trabalham a temática solo em sala de aula. Comparando os resultados obtidos pelas autoras com os da presente pesquisa, pôde-se constatar que, analogamente as autoras citadas, as questões com o menor número de acertos foram aquelas relacionadas a meio ambiente e sustentabilidade e solo, sinalizando a lacuna existente.

Em trabalho de Dahmer e Nascimento (2014) as autoras constataram que os professores de Geografia são um dos que mais trabalham e se envolvem nas ações relacionadas ao meio ambiente nas escolas. Nesse sentido, após a intervenção desse trabalho através da oficina, foram justamente esses profissionais que apresentaram os melhores resultados.

\section{Conclusão}

Os materiais didático-pedagógicos confeccionados pelos discentes do grupo PET Solos da UESC e apresentados para os professores da rede pública de Educação Básica, através do formato escolhido de oficina para a abordagem e interação, foram eficazes no processo de ensino-aprendizagem, tendo em vista que, após a análise quantitativa, observou-se maior totalidade de acertos após a intervenção desse trabalho.

A prática da Oficina da Ciência da Terra como formato para a abordagem e interação auxiliar no processo de ensino-aprendizagem se constituiu numa ferramenta importante para o exercício docente na Educação Básica. A ideia posta em prática através desta pesquisa constatou, por meio dos resultados, que esse é um modelo educacional que deve ser utilizado de maneira mais ampla nos diversos colégios públicos da microrregião Ilhéus-Itabuna (Bahia). Além disso, a relevância dos grupos PET na construção do conhecimento a partir da experiência reflexiva dos discentes, na integração entre universidade e sociedade, na divulgação científica, configuram-se como propulsores de casos aptos à divulgação pelos meios de comunicação, pois esses projetos são de interesse público, logo, noticiáveis.

\section{Referências}

AMARA, R. de C. B. de M.; BITTENCOURT, R. N.; ARAÚJO, B. P. de; ROCHA, C. C. S.; COSTA, I. L. M. da. Role-playing game no ensino híbrido: práticas interdisciplinares. Revista Ciência Atual, v. 13, n. 1, 2019.

AMORIM, R. R.; MOREAU, A. M. S. S. (2003) Avaliação do conteúdo da ciência do solo em livros didáticos de Geografia do Ensino Médio. GeoUERJ. Rio de Janeiro, p. 74-81, nov. Edição especial.

BACICH, L.; MORIN, J. Aprender e ensinar com foco na educação híbrida. Revista Pátio, n. 25, jun. 2015.

- Metodologias ativas para uma educação inovadora: uma abordagem teórico-prática. Porto Alegre: Penso, 2018.

DAHMER, R. L.; NASCIMENTO, R da S. (2014) Práticas de docência da geografia escolar e ações ambientais pedagógicas na educação básica. Pesquisar - Revista de Estudos e Pesquisas em Ensino de Geografia, Florianópolis, SC, v. 1, n. 1, out. 
DREBES, L. M.; ORTIGARA, C.; ARTUZO, F. D.; JANDREY, W. F.; RODRIGUES DA SILVA, V. A dinâmica do Programa de Educação Tutorial (PET). Enciclopédia Biosfera, Centro Científico Conhecer, Goiânia, v. 8, n. 15, p. 2334, 2012.

EMBRAPA. (2018) Sistema brasileiro de classificação de solos. 5a . ed. Brasília: Embrapa, 2018.

FARNDON, J. (1994) Guia prático de ciências. São Paulo: Editora Globo.

FERREIRA, M. M. Produção científica na biblioteconomia: as pesquisas realizadas no Programa de Educação Tutorial (PET) e seus reflexos na formação acadêmica. Revista EDICIC, v.1, n.4, p. 99-108, out./dez., 2011.

GOHN, M. da G. (1999) Educação não formal e cultura política: impacto sobre o associativismo do terceiro setor. São Paulo: Cortez.

IBGE. (2015) Manuais técnicos em geociências, número 4. Manual técnico de pedologia,

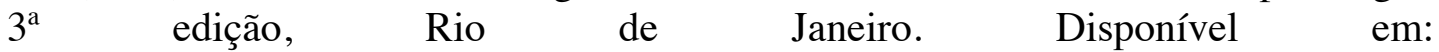
$<$ https://biblioteca.ibge.gov.br/visualizacao/livros/liv37318.pdf>. Acesso em: 21 out. 2020 .

JURGINA, L. Q.; CORRÊA, D. da S.; SELBACH, G.; MARQUES, F. de S.; ROSA JUNIOR, L. S. da. (2019) O legado didático da convergência de interface tangível com realidade aumentada no magistério de cartografia tridimensional. Revista ComInG, v. 4, n. 1. Disponível em: <https://periodicos.ufsm.br/coming/article/view/37733>. Acesso em: 22 out. 2020.

KARLING, A. A. (1991) A didática necessária. São Paulo: Ibrasa.

LABURÚ, C. E.; CARVALHO, M.; BATISTA, I. L. (2001) Controvérsias construtivistas. Caderno Catarinense de Ensino de Física, v.18, n.2, p.152-181, ago.

LÁZARO, A. C.; SATO, M. A. V.; TEZANI, T. C. R. Metodologias ativas no ensino superior: o papel do docente no ensino presencial. Anais. CIET, EnPED: 2018 Educação e Tecnologias: Docência e mediação pedagógica .

LEPSCH, I. F. (2011) 19 lições de pedologia. São Paulo: Oficina de Textos.

LIMA, J. A. (2002) As culturas colaborativas nas escolas: estruturas, processos e conteúdos. Porto, Portugal: Porto Editora.

LOCATELLI, O. C.; HENDGES, C. D.; MALLMANN, E. M.; CATAPAN, A. H. (2009) A educação ambiental na região do alto Uruguai: sustentabilidade e tecnologias de comunicação digital nos currículos da educação básica. Anais. V Congresso Nacional de Excelência em Gestão. Gestão do Conhecimento para a Sustentabilidade. Niterói, RJ, Brasil.

MARTIN, M. da G. M. B. O Programa de Educação Tutorial-PET: formação ampla na graduação. 2005. 108 f. Dissertação (Mestrado em Educação) - Setor de Educação, Universidade Federal do Paraná, Curitiba, 2005.

MOACIR, G. (1996) Histórias das ideias pedagógicas. São Paulo: Editora Ática.

MONTENEGRO, G. A. (2005) Inteligência visual e 3-D. São Paulo: Edgard Blücher. 
MORAN, J. Metodologias ativas e modelos híbridos na educação. In: Novas tecnologias digitais: reflexões sobre mediação, aprendizagem e desenvolvimento. Curitiba: CRV, 2017, p.23-35.

Mudando a educação com metodologias ativas. In: Coleção mídias contemporâneas. Convergências midiáticas, educação e cidadania: aproximações jovens, v. 2, 2015.

PAVIANI, N. M. S.; FONTANA, N. M. (2009) Oficinas pedagógicas: relato de uma experiência. Conjectura, v. 14, n. 2, maio/ago. Disponível em: $<$ http://www.ucs.br/etc/revistas/index.php/conjectura/article/viewFile/16/15>. Acesso em: 21 out. 2020.

PERES, S.; BOSCARIOLI, C.; FERRARI, A.; COSTA, C.; ALVES, C.; SALLES, C. de; BRUSCATTO, G.; GABRIELA SILVA; LUCAS DA SILVA; FERNANDO DE SOUZA, L.; TEIXEIRA, M.; DELMONDES, P.; WAGNER, P. O Programa de Educação Tutorial no contexto da graduação em Computação: Perfis, percepções e reflexões. 2014. Anais. XXII Workshop sobre Educação em Computação.

PIAGET, J.; INHELDER, B. (1971) O Desenvolvimento das qualidades físicas na criança. Rio de Janeiro: Zahar Editores.

POLICARPO, L. M.; FUHR, G. T.; LIBRELOTTO, G. R. (2019) Uma abordagem para apoio em laboratórios computacionais em escolas públicas de ensino infantil. Revista ComInG, v. $4, \quad$ n. 1.4 Disponível em: <https://periodicos.ufsm.br/coming/article/view/38072>. Acesso em: 22 out. 2020.

POZO, J. I.; CRESPO, M. A. G. (1998) Aprender y enseñar ciencia. Madrid: Morata.

RODRIGUES, M. C.; ALVES, M. A. P.; ALMEIDA, R. D. de; MIGUEL DA SILVA, R. de L. Intervenção em habilidades cognitivas e metacognitivas de leitura em alunos do Programa de Educação Tutorial - PET. Psicologia: Teoria e Prática, v. 16, n. 1, jan.-abr., 2014, p. 181-190.

ROSIN, S. M.; GONÇALVES, A. C. A.; HIDALGO, M. M. Programa de Educação Tutorial: Lutas e Conquistas. Revista ComInG, v. 2, n. 1, 2017.

ROTHSTEIN, J. M. E. M. do B.; GONÇALVES SANTOS, M. da G. Ensino híbrido: enlace de experiências pedagógicas em metodologias ativas. Revista Olhares, v. 1, n. $7,2017$.

SOUZA, D. C.; ANDRADE, G. L. P.; NASCIMENTO JUNIOR, A. F. (2008) Produção de material didático-pedagógico alternativo para o ensino do conceito pirâmide ecológica: um subsídio a educação cientifica e ambiental. In: Fórum Ambiental da Alta Paulista, São Paulo. Anais: ANAP, CD-ROM.

STEFENON, D. L. (2014) As concepções de professores da rede pública de ensino de Irati/PR sobre o currículo da geografia na escola básica. Pesquisar - Revista de Estudos e Pesquisas em Ensino de Geografia. Florianópolis, SC, v. 1, n. 1.

TEIXEIRA, W.; TOLEDO, M. C. M. de; FAIRCHILD, T. R.; TAIOLI, F. (2007) Decifrando a terra. São Paulo: Editora Nacional.

TORINA, H. F.; ALMEIDA, L. O.; PAULA, J. S. de. História do Programa de Educação Tutoria da FMRP-USP. Medicina, Ribeirão Preto, 2016, n. 49, v. 4, p. 374-380. 
TRUMPER, R. (2003) The physics laboratory - a historical overview and future perspectives. Science \& Education, Dordrecht, v. 12, p. 645-670.

VIGOTSKY, L. S. (1987) Pensamento e linguagem. São Paulo: Martins Fontes.

WALTER, S. A.; GOMES, L.; FREGA, J. R.; TONTINI, G.; VIEIRA DA SILVA, W. Educação tutorial: revitalizando ensino-aprendizagem e pesquisa em administração. Revista de Administração FACES Journal, v. 9, n. 4, set.-dez., 2010, p. 87-104.

ZABALA, A. (1998) A pratica educativa: como ensinar. Porto Alegre: Artmed. 